\title{
Fatal Hypersensitivity Pneumonitis from Exposure to Fusarium vasinfectum in a Home Environment: A Case Report
}

\author{
Scott D. Dickson ${ }^{a}$ Michael S. Tankersley ${ }^{b}$ \\ aDepartment of Allergy and Immunology, 56th MDG/SGOMA, Luke Air Force Base, Glendale, Ariz., and \\ ${ }^{b}$ Department of Allergy and Immunology, Wilford Hall Ambulatory Surgical Center, Joint Base San Antonio \\ Lackland, San Antonio, Tex., USA
}

\section{Established Facts}

- Hypersensitivity pneumonitis (HP) is a complex non-IgE-mediated pulmonary inflammatory disease triggered by the inhalation of multiple occupational and avocational antigens.

- The prognosis is generally favorable with early detection and prompt removal from the causative environment.

\section{Novel Insights}

- Nonoccupational cases of HP are increasing.

- Fatalities from HP are rare.

- Continuous, intense exposure to the offending antigen can lead to death.

\section{Key Words}

Hypersensitivity pneumonitis · Fusarium vasinfectum · Mold · Fatal case $\cdot$ Chronic exposure $\cdot$ Home environment

\begin{abstract}
Background: Hypersensitivity pneumonitis (HP) is a rare, non-IgE-mediated inflammatory lung disease caused by inhalational exposure to various antigens found in occupational, avocational and home environments. The prognosis is favorable with early detection and prompt removal of the causative agent, and fatalities are unusual. We present a fatal case of HP caused by chronic exposure to Fusarium vasinfectum mold in the home. Case Report: A 37-year-old white male presented with a 6-month history of progressively
\end{abstract}

worsening dyspnea, cough, weight loss and fatigue associated with the self-renovation of his water-damaged, moldinfested mobile home. Evaluation included a physical examination (hypoxia, inspiratory crackles and expiratory rhonchi), baseline pulmonary function testing (mixed obstructive/ restrictive pattern), chest computed tomography (bronchiectasis, fibrosis and diffuse interstitial involvement), bronchoalveolar lavage (macrophages 20\%, lymphocytes $28 \%$ and neutrophils 52\%) and transbronchial biopsy (interstitial fibrosis and chronic inflammatory infiltrate). Mold culture from the home grew out $F$. vasinfectum. An Ouchterlony double diffusion technique documented high antibody titer to $F$. vasinfectum. Despite aggressive intravenous corticosteroid treatment, the patient's lung function declined to the extent that he could not be removed from ventilator support

\section{KARGER 125}

(c) 2015 S. Karger AG, Base

$1018-2438 / 15 / 1662-0150 \$ 39.50 / 0$

E-Mail karger@karger.com

www.karger.com/iaa
Correspondence to: Dr. Dr. Scott D. Dickson

Department of Allergy and Immunology, 56th MDG/SGOMA

7219 North Litchfield Road

Luke Air Force Base, AZ 85309 (USA)

E-Mail scott.dickson.5@us.af.mil 
following an open lung biopsy, eventually resulting in death. Conclusion: This is the first reported case of fatal HP related to an acute exacerbation of a chronic form of HP following continuous and intense exposure to $F$. vasinfectum. Although uncommon, a high index of suspicion for HP is necessary in patients with progressive respiratory symptoms and known environmental antigen exposure. With early detection and prompt removal of the causative antigen, HP prognosis is generally favorable, but can progress to fatal disease with continued exposure.

(c) 2015 S. Karger AG, Basel

\section{Introduction}

Hypersensitivity pneumonitis (HP), alternatively known as extrinsic allergic alveolitis or allergic interstitial pneumonitis, is a rare, highly complex non-IgE-mediated inflammatory disease of lung parenchyma, alveoli and airways in response to the inhalation of various antigens. The exact pathogenic mechanism is not fully understood. Both antibody- and cell-mediated immunologic responses may be involved $[1,2]$. Numerous agents have been identified, including various species of fungi, bacteria and protozoa, animal and plant proteins, and inorganic lowmolecular-weight chemicals. Classically, HP has been identified as a disease of specific occupations (e.g. farmer's lung disease) and unique recreational activities (e.g. pigeon breeder's disease). However, more recent data suggests an increase in cases of HP secondary to somewhat ordinary home exposures (e.g. pet bird antigens, feather bedding, contaminated hot tubs and household indoor molds) [2-5]. The prognosis is generally favorable with early detection and prompt removal of the causative agent, and fatalities are unusual. We present a fatal case of $\mathrm{HP}$ as a complication of an open lung biopsy during an acute exacerbation of chronic HP, secondary to continuous and intense daily exposure to Fusarium vasinfectum mold in a home environment.

\section{Case Report}

A 37-year-old white male presented with a 6-month history of progressively worsening dyspnea on exertion, $20 \mathrm{lb}(9.1 \mathrm{~kg})$ weight loss, fatigue and nonproductive cough. Over the 6-month period, the patient had been self-renovating his 10 -year-old water-damaged mobile home in which he had lived for 5 years. He reported finding extensive mold involvement under the side panels of the mobile home. His health had significantly deteriorated to the point of having difficulty walking even short distances, prompting him to seek emergency care.

Fatal Hypersensitivity Pneumonitis from

F. vasinfectum Exposure

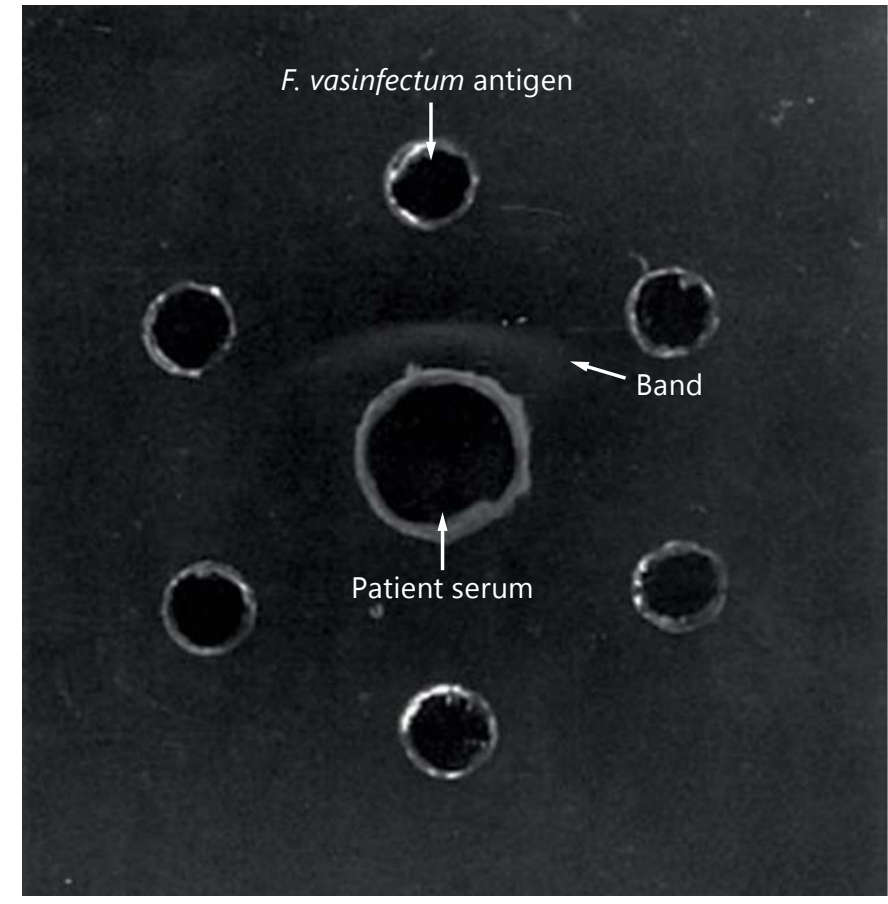

Fig. 1. Ouchterlony double diffusion technique showing a precipitin band between patient serum and $F$. vasinfectum antigen.

The patient's past medical history revealed that 3 years prior an abnormal chest X-ray was found during a routine occupational medical evaluation prompting pulmonary function testing. The pulmonary function test indicated a mixed obstructive/restrictive pattern, leading to a diagnosis of possible asthma. The patient reported only minimal dyspnea with exertion at that time. The patient was advised to cease tobacco smoking and was started on daily asthma controller therapy. During the subsequent 3 years leading up to presentation, the patient reported recurrent episodes of cough and dyspnea triggered by exercise, viral upper respiratory infections, laughing and exposure to strong odors. He reported relatively stable symptoms on daily controller therapy and, as needed, use of short-acting $\beta$-agonists up until the time he began renovating the mold-contaminated mobile home.

An initial physical examination in the emergency department revealed a room air pulse oximetry of $88 \%$ and audible pulmonary inspiratory crackles and expiratory rhonchi. The examination was otherwise unremarkable. Baseline pulmonary function tests indicated a mixed obstructive/restrictive pattern (FVC 1.8/35\%, $\mathrm{FEV}_{1}$ $1.29 / 32 \%, \mathrm{FEV}_{1} / \mathrm{FVC} 72 \%$, DLCO $31 \%$ and TLC $32 \%$ ). A highresolution computed tomography chest scan revealed bronchiectasis, pulmonary fibrosis and diffuse interstitial involvement. Bronchoalveolar lavage revealed a predominance of neutrophils (52\%), with lymphocytes (28\%) and macrophages (20\%) also identified. A transbronchial biopsy showed interstitial fibrosis and scant chronic inflammatory infiltrate. Mold cultures obtained from scrapings from the interior walls of the patient's mobile home isolated F. vasinfectum alone. Both a commercially available serum precipitin mold panel (Northwestern University Feinberg School

Int Arch Allergy Immunol 2015;166:150-153 
of Medicine CLIA Laboratory, Chicago, Ill., USA) and an Ouchterlony double diffusion test demonstrated the presence of serum antibodies to $F$. vasinfectum (fig. 1).

The patient was placed on 2 liters of oxygen and treated with intravenous (IV) glucocorticoids. Despite high doses of IV glucocorticoids, the patient's clinical status continued to decline prompting an air evacuation from Scott Air Force Base, Illinois, to Wilford Hall Medical Center, San Antonio, Texas, for more definitive care.

Continued deterioration of the patient's lung status led to the decision to perform an open lung biopsy. Histologic findings on light microscopy were consistent with usual interstitial pneumonia (UIP). Following the open lung biopsy, the patient could not be weaned from ventilator support and had continued respiratory decline resulting in death on hospital day 21.

\section{Discussion}

$\mathrm{HP}$ is an uncommon immune-mediated pulmonary disease characterized by symptoms of dyspnea and cough due to inhalation of occupational and environmental antigens. HP can present in acute, subacute or chronic forms depending on the type, intensity and duration of exposure to the inciting agent [1]. The diagnosis of HP requires a correlation between exposure history and symptoms supported by physical examination findings, and a variety of diagnostics tests to include serum precipitins, pulmonary function tests, radiographic findings, histology data from bronchoalveolar lavage and lung biopsy, or direct inhalational provocation testing $[2,6]$. The prognosis is generally favorable with early identification, prompt removal of the offending antigen and symptomatic treatment with corticosteroids [7]. However, continued antigen exposure can lead to a permanent loss in lung function, irreversible pulmonary fibrosis and even premature death [1].

Fatal HP is rare but has occurred following chronic exposure to avian-protein antigens, thermophilic actinomycetes in moldy hay, and following treatment with docetax$\mathrm{el}$, an inorganic low-molecular-weight antineoplastic drug $[1,8,9]$. In the cases of avian-induced HP, a higher mortality rate was seen in males older than 44 years of age with prolonged antigen exposure, evidence of honeycombing on chest imaging, and histological findings consistent with an UIP pattern on lung biopsy $[8,10]$.

To our knowledge, we present the first reported HP fatality related to chronic exposure to $F$. vasinfectum in a home environment. Fusarium is a large genus of filamentous fungi widely distributed on plants and in soil. The spores of Fusarium are large (about $40 \mu \mathrm{m}$ in length) and sickle shaped, with pointed ends [11]. Despite their large size, it has been hypothesized that Fusarium spores re- lease small antigenic material that can reach the terminal alveoli, where an immunologic response results $[2,12$, 13]. Different species of Fusarium have been isolated in a number of HP patients with exposures in both occupational and home settings [2, 4, 14-17], none of which were fatal. Our patient reported mild but recurrent symptoms of cough and dyspnea over a 3-year span, which were misinterpreted as asthma, while living unknowingly in his F. vasinfectum-contaminated mobile home. The diagnosis of HP was not suspected until after the patient developed significant dyspnea on exertion, daily fatigue and weight loss while attempting to repair the newly discovered mold damage to the inner surface of the woodsiding on his mobile home. Despite removal of the patient from the mobile home and aggressive IV corticosteroid treatment, the patient's lung function declined to the point that he could not be removed from ventilator support following the open lung biopsy. The patient is believed to have died as a complication of an open lung biopsy during an acute exacerbation of a chronic form of $\mathrm{HP}$, following continuous and intense exposure to $F$. vasinfectum in his home, as demonstrated by a history of known antigen exposure, recurrent symptoms and weight loss, the presence of inspiratory crackles on physical examination, positive cultures obtained from the home, and the presence of positive precipitating antibodies to $F$. vasinfectum in the patient's serum. The diagnosis of HP is further supported by the finding of chronic interstitial inflammation and diffuse pulmonary fibrosis on highresolution computed tomography and histologic evidence of UIP on the surgical biopsy. Morell et al. [5] described 20 out of $46(43 \%)$ patients who had initially been diagnosed with idiopathic pulmonary fibrosis as per the current criteria [18], but were later diagnosed with chronic HP once exposure history and other diagnostic findings were taken into consideration.

\section{Conclusion}

Although rare, a high index of suspicion for HP is necessary in the evaluation of a patient presenting with progressive respiratory symptoms and a history suggesting antigen exposure in the home, in addition to the more traditional occupational and recreational settings. Environmental agents should also be considered in patients with idiopathic interstitial lung disease. Prognosis is usually favorable when detected early and the causative antigen is avoided or removed. HP can progress to a fatal disease with continued exposure, as seen in this case. 


\section{Disclosure Statement}

Both authors have no conflicts of interest to declare pertaining to this article and approve its submission to International Archives of Allergy and Immunology. The opinions expressed on this docu- ment are solely those of the authors and do not represent an endorsement by or the views of the United States Air Force, the United States Army, the Department of Defense, or the United States Government.

\section{References}

1 Patel AM, Ryu JH, Reed CE: Hypersensitivity pneumonitis: current concepts and future questions. J Allergy Clin Immunol 2001;108: 661-670.

2 Ramirez RM, Jacobs RL: Hypersensitivity pneumonitis by Fusarium vasinfectum in a home environment. J Allergy Clin Immunol Pract 2014;2:483-484.

3 Hanak V, Golbin JM, Ryu JH: Causes and presenting features in 85 consecutive patients with hypersensitivity pneumonitis. Mayo Clin Proc 2007:82:812-816.

4 Jacobs RL, Andrews CP, Coalson J: Organic antigen-induced interstitial lung disease: diagnosis and management. Ann Allergy Asthma Immunol 2002;88:30-41.

5 Morell F, Villar A, Montero MA, Munoz X, Colby TV, Pipvath S, et al: Chronic hypersensitivity pneumonitis in patients diagnosed with idiopathic pulmonary fibrosis: a prospective case-cohort study. Lancet Respir Med 2013;1:685-694.

6 Lacasse Y, Selman M, Costabel U, Dalphin J-C, Ando M, Morell F, et al: Clinical diagnosis of hypersensitivity pneumonitis. Am J Respir Crit Care Med 2003;168:952-958.
7 Kokkarinen JI, Tukiainen HO, Terho EO: Effect of corticosteroid treatment on the recovery of pulmonary function in farmer's lung. Am Rev Respir Dis 1992;145:3-5.

8 Zacharisen M, Schoenwetter W: Fatal hypersensitivity pneumonitis. Ann Allergy Asthma Immunol 2005;95:484-487.

9 Gurram MK, Pulivarthi S, McGary CT: Fatal hypersensitivity pneumonitis associated with docetaxel. Tumori 2013;99:e100-e103.

10 Gaxiola M, Buendia-Roldan I, Mejia M, Carillo G, Estrada A, Navarro MC, et al: Morphologic diversity of chronic pigeon breeder's disease: clinical features and survival. Respir Med 2011;105:608-614.

11 Adkinson NF, Boehner B, Busse W, Holgate S, Lemanske R, Simons FE, et al: Middleton's Allergy, ed 7. Philadelphia, Elsevier, 2009.

12 Selman M, Pardo A, King TE: Hypersensitivity pneumonitis: insights in diagnosis and pathology. Am J Respir Crit Care Med 2013;186: 314-324.

13 Badorreck P, Dick M, Emmert L, Schaumann F, Koch W, Hecker H, et al: Pollen starch granules in bronchial inflammation. Ann Asthma Allergy Immunol 2012;109:208-214.
14 Fishwick D, Tate P, Elms J, Robinson E, Crook B, Gallagher F, et al: Respiratory symptoms, immunology and organism identification in contaminated metalworking fluid workers. What you see is not what you get. Occup Med 2005;55:238-241.

15 Merget R, Sander I, Rozynek P, Raulf-Heimsoth M, Bruening T: Occupational hypersensitivity pneumonitis due to molds in an onion and potato sorter. Am J Ind Med 2008;51: 117-119.

16 Metzger F, Haccuria A, Reboux G, Nolard N, Dalphin JC, De Vuyst P: Hypersensitivity pneumonitis due to molds in a saxophone player. Chest 2010;138:724-726.

17 Lee SK, Kim SS, Nahm DH, Park HS, Oh YJ, Park KJ, et al: Hypersensitivity pneumonitis caused by Fusarium napiforme in a home environment. Allergy 2000;55:1190-1193.

18 Raghu G, Collard HR, Egan JJ, Martinez FJ, Behr J, Brown KK, et al: An official ATS/ERS/ JRS/ALAT statement: idiopathic pulmonary fibrosis: evidence-based guidelines for diagnosis and management. Am J Respir Crit Care Med 2011;183:788-824. 